\title{
GCU
}

Glasgow Caledonian

University

University for the Common Good

\section{Sustainable machining: process energy optimisation of wire electrodischarge machining of Inconel and titanium superalloys}

Gamage, Janaka R.; DeSilva, Anjali K.M.; Chantzis, Dimitrios; Antar, Mohammad

Published in:

Journal of Cleaner Production

DOI:

10.1016/j.jclepro.2017.06.186

Publication date:

2017

Document Version

Author accepted manuscript

Link to publication in ResearchOnline

Citation for published version (Harvard):

Gamage, JR, DeSilva, AKM, Chantzis, D \& Antar, M 2017, 'Sustainable machining: process energy optimisation of wire electrodischarge machining of Inconel and titanium superalloys', Journal of Cleaner Production, vol. 164, pp. 642-651. https://doi.org/10.1016/j.jclepro.2017.06.186

\section{General rights}

Copyright and moral rights for the publications made accessible in the public portal are retained by the authors and/or other copyright owners and it is a condition of accessing publications that users recognise and abide by the legal requirements associated with these rights.

Take down policy

If you believe that this document breaches copyright please view our takedown policy at https://edshare.gcu.ac.uk/id/eprint/5179 for details

of how to contact us. 
Word count: 6718

Sustainable machining: Process energy optimisation of wire electrodischarge machining of Inconel and Titanium superalloys

Janaka R. Gamagea, Anjali K.M. DeSilvaa,*, Dimitrios Chantzis ${ }^{b}$, Mohammad Antarb $^{\mathrm{b}}$

aSchool of Engineering and Built Environment, Glasgow Caledonian University, Glasgow, Scotland, UK bThe Manufacturing Technology Centre, Coventry, UK

* Corresponding author. Tel.: +44-141-331-3522; fax: + 44-141-331-3005. E-mail address: ade@gcu.ac.uk

\begin{abstract}
Process energy optimisation is vital in view of the environmental performance of electrodischarge machining (EDM). This research is focused on identifying the significant parameters that optimise the process energy consumption of wire EDM (WEDM) of superalloys: Inconel-718 and Ti64Al4V. Four general parameters: workpiece material, workpiece thickness, wire material, and wire diameter; and four discharge parameters: gap voltage, peak current, pulse-ON time, and pulse-OFF time were tested against specific energy consumption (SEC) and surface quality of the cut. Taguchi design of experiments and analysis of variance (ANOVA) methods were used for experimentation and analysis. The Green House Gas Protocol is used to analyse potential reductions in carbon emissions. The results indicate that preferred parameters to minimise the specific energy consumption are workpiece thickness, wire material, wire diameter, and pulse-OFF time in the order of significance. It is found that $2 / 3^{\text {rd }}$ of the total energy was consumed during non-working hours which can potentially be saved. Further, the reduction of carbon emissions corresponds to non-working energy consumption of the machines is also presented.
\end{abstract}

Keywords: Sustainable machining; WEDM; Process energy, Superalloys

\title{
1 Introduction
}

\section{Glossary of terms}

HB Higher-the-Better

LB Lower-the-Better

MRR Material Removal Rate $\left(\mathrm{mm}^{3} / \mathrm{min}\right)$

P-OFF Pulse Off time ( $\mu$ s)

P-ON Pulse On time ( $\mu \mathrm{s})$

$\mathrm{R}_{\mathrm{a}} \quad$ Average Surface Roughness $(\mu \mathrm{m})$

SEC Specific Energy Consumption(kJ/ $\mathrm{mm}^{3}$ ) 


$\begin{array}{ll}\text { SN ratio }(\eta) & \text { Signal to Noise Ratio } \\ \mathrm{SS}_{\mathrm{BW}} & \text { Sum of Squares-Between Groups } \\ \mathrm{SS}_{\mathrm{T}} & \text { Sum of Squares-Total } \\ \mathrm{SS}_{\mathrm{W}} & \text { Sum of Squares-Within Groups }\end{array}$

The energy consumption by the industry sector, which accounts for $42.5 \%$ of the total world electrical energy consumption in 2014, has increased threefold from 1973, amounting to 725 tonnes of oil equivalent (8,432 TWh) according to IEA (2016). The metal manufacturing industry is the fourth largest energy consumer in the US with 1.6 quadrillions Btu $\left(1.7 \times 10^{15} \mathrm{~J}\right)$ of energy used in 2010 (USEIA, 2016). Machining is one of the most widely used manufacturing processes (Munoz and Sheng, 1995) and thus it shares a significant portion of the manufacturing energy (Gutowski et al., 2006). As the world's electricity generation is mainly by fossil sources, amounting to $67 \%$ of the total of 23,816 TWh in 2014 (IEA, 2016), savings on the electrical energy help reduce the rate of extraction of fossil resources, subsequently leading to environmental savings.

Electrodischarge machining (EDM) is considered at least 1000 times more energy intensive than comparable conventional machining processes due to its low material removal rates (Li and Kara, 2015). EDM uses the energy of precisely controlled sparks between the tool electrode and the workpiece to remove material by localised melting and evaporation. The temperature at the point of discharge could be more than $12,000{ }^{\circ} \mathrm{C}$ (Sutherland and Gunter, 2001).The machining surface is usually immersed in a non-conducting dielectric fluid. In EDM wire cutting (WEDM), a spool of continuously fed wire is used as the tool electrode and deionized water as the dielectric. The rate of energy consumption of EDM could vary based on the construction of the machine tool and machining parameters. The supply power ranges around $5-8 \mathrm{~kW}$ for some machines when machining steel (AISI P20) (Gamage and DeSilva, 2016). The highest energy consuming subunits are usually the chillers/water coolers and the pumps. Dhanik et al. (2011) have identified two types of energy consuming subunits: process dependent units such as injection pumps and spark generators and process independent units such as filling pumps, filter pumps, auxiliary pumps and water coolers. There are variations, however, depending on the established algorithms of each machine tool builder.

Since EDM is generally used for hard-to-cut materials, such as nickel and titanium-based alloys, the material used in this research was an aerospace superalloy. Gamage et al. (2016) attributed electrical energy as the largest contributor accounting for $64 \%$ of the total environmental impact for one-hour of WEDM of steel (AISI P20). For diesinking EDM operations, the share of environmental impact caused by electrical energy ranges about $50-60 \%$ of the total impact during one-hour of roughing of steel with a copper tool (Gamage et al., 2016; Kellens et al., 2011). Thus, it can be said that electrical energy accounts for the majority share of the total environmental impact of EDM. The unit process data for 
environmental impact assessment are scarce for unconventional manufacturing processes despite these processes being used widely in the industry (Duflou et al., 2012).

This paper analyses the process energy consumption of WEDM which is an extension of the research published titled 'Process level environmental performance of EDM of aluminium (3003) and steel (AISI P20)'(Gamage et al., 2016). Experiments were conducted in a state-of-the-art research facility in the UK. Two workpiece materials (Inconel-718 and Ti6Al4V) with three thicknesses, two wire materials (copper and brass) with two diameters $(0.25 \mathrm{~mm}$ and $0.30 \mathrm{~mm})$ were used.

Taguchi design of experiments was used to assess the influence of pulse times, discharge current, and voltage. Integrating all the parameter combinations, a total of 216 separate cuts were performed. The specific energy consumption (SEC), the material removal rate (MRR), and the average surface roughness $\left(R_{a}\right)$ were calculated as the performance characteristics for each of the cuts. Taguchi analysis was used to find the optimum discharge parameters for lower-the-better SEC and $\mathrm{R}_{\mathrm{a}}$ (Section 2.4.1). Analysis of variance (ANOVA) test was used to identify and prioritise the significant input parameters. Furthermore, an analysis of the potential energy savings and the subsequent reduction in carbon emissions from keeping the machines switched off during non-working hours is also presented. This enabled the prioritised parameters for the improved process energy performance of WEDM to be identified, as well as the sustainability implication of sensible operating practices, and further research directions for improved sustainability of unconventional machining.

\section{Research approach}

\subsection{Design of experiments}

As shown in Figure 1, three workpiece thicknesses: 5, 10, and 15 mm, of both Inconel-718 and Ti6Al4V superalloys were used. Two types of wires, copper and brass, each with two diameters, $0.25 \mathrm{~mm}$ and $0.30 \mathrm{~mm}$, were used. 


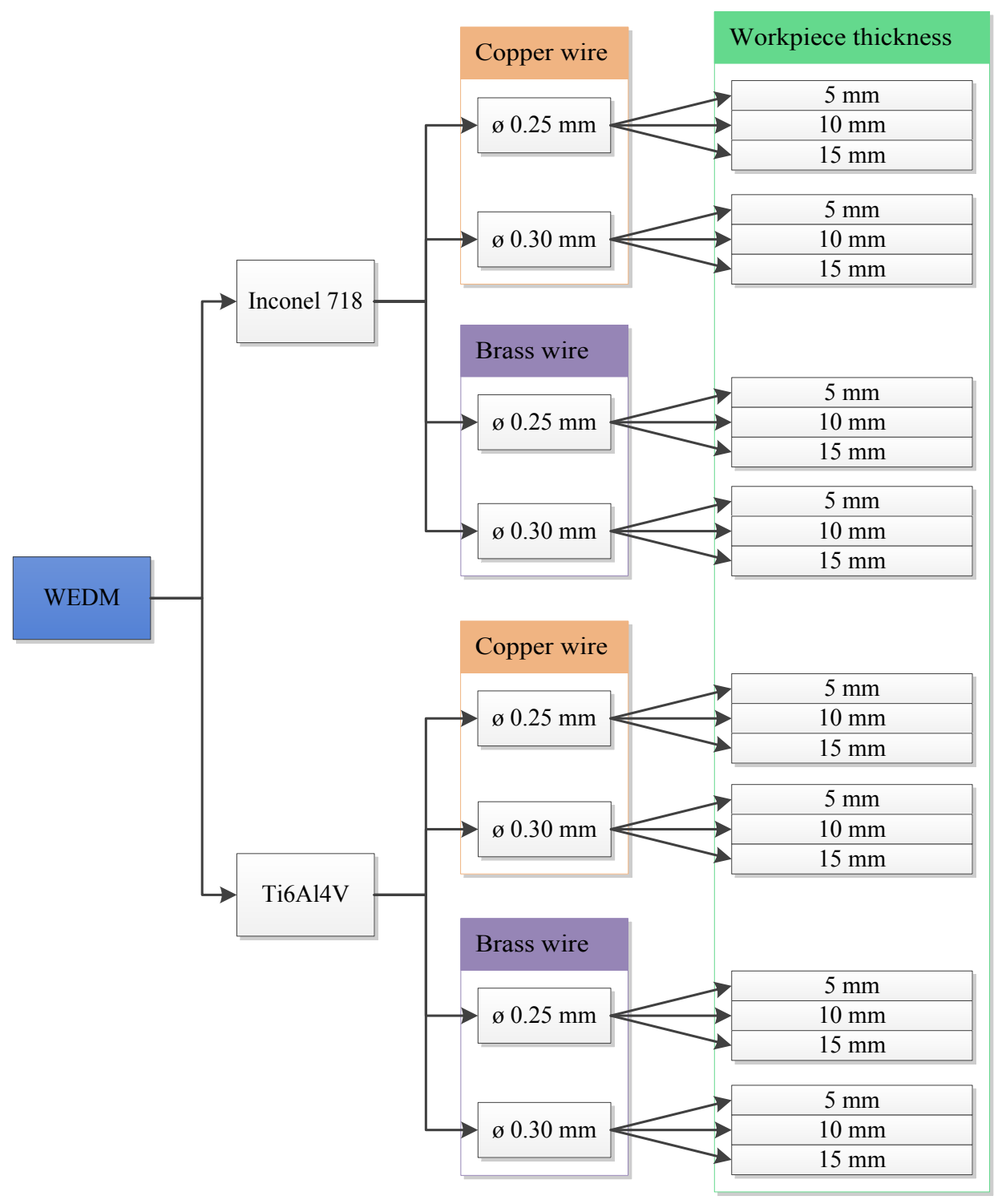

Figure 1: Overview of experiments

Each of the combinations shown in Figure 1 was then tested with 9 experiments as suggested by the Taguchi L9 array with 3-level, 4-factor design. Selecting of parameters among a large number of variables available, such as pulse ON/OFF times, table feed rate, flushing pressure, wire tension, and wire velocity, are heavily dependent on the operator skills with most of the machines (Ho et al., 2004; Huang and Liao, 2003). However, modern machines, such as the one used in this research, offer the luxury of proposing a standard set of parameters for a given output quality required with a unit-less scale of 1-100. This helps the operator to figure out a better compromise between the output quality and the speed of machining. Considering previous studies on WEDM parameter optimisation (Garg et al., 2014; Manna and Bhattacharyya, 2006; Tarng et al., 1995), four parameters, pulse-ON, pulse-OFF, gap voltage, and peak current, were selected to test with 3-levels of variations as shown in Table 1. The selection was based on previous studies of WEDM parameter optimisation. The other parameters such as wire tension, wire feed, and table feed were kept constant. The middle level (level-2) was selected based on the machine suggested values for the given scenario. The wide range/variety of parameters caused the level-2 to vary significantly as can be seen with pulsation times in Table 1 . 
However, the gaps of variation between the levels were kept constant in each case. Then the Levels 1 and 3 were manually overridden. Parameters were set only for rough cuts as there was no objective of achieving specific surface finish level. Additionally, the finishing cuts with altered parameter settings complicate the energy consumption analysis.

Table 1: Machining parameters with levels of variation

\begin{tabular}{llll}
\hline Parameter & Level-1 & Level-2 & Level-3 \\
\hline Pulse-ON $(\mu \mathrm{s})$ & $0.3-0.6$ & $0.5-0.8$ & $0.7-1.0$ \\
Pulse-OFF $(\mu \mathrm{s})$ & $3-15$ & $10-25$ & $17-35$ \\
Voltage $(\mathrm{V})$ & 60 & 80 & 100 \\
Peak current $(\mathrm{A})$ & 3 & 5 & 7 \\
\hline
\end{tabular}

\subsection{Workpiece and tool materials}

Both alloys tested are widely used in the aerospace industry for rotating or stationary components of the hot end of jet engines due to their ability to retain the mechanical and chemical properties at elevated temperatures. Inconel-718 is a corrosion resistant, high strength nickel-chromium alloy is typically used in temperature ranges from $-423^{\circ} \mathrm{F}$ to $1300^{\circ} \mathrm{F}$. Typical applications include liquid fuelled rocket components, casings and parts for aircraft and land-based gas turbines, and cryogenic tankage (Special Metals Corporation, 2007). The workpieces (Inconel) used for the experiments were vacuum induction melted-electro slag remelted, hot rolled plates of different thicknesses. The chemical composition of Inconel-718 is presented in Table 2.

Table 2: Chemical composition of Inconel 718 (wt.\%)

\begin{tabular}{llllllllllllllll}
\hline $\mathrm{Ni}$ & $\mathrm{Cr}$ & $\mathrm{Fe}$ & $\mathrm{Nb}$ & $\mathrm{Mo}$ & $\mathrm{Ti}$ & $\mathrm{Al}$ & $\mathrm{Co}$ & $\mathrm{C}$ & $\mathrm{Mn}$ & $\mathrm{Si}$ & $\mathrm{Cu}$ & $\mathrm{Ta}$ & $\mathrm{P}$ & $\mathrm{S}$ & $\mathrm{B}$ \\
\hline 50.0 & 17.0 & 15.0 & 4.75 & 2.80 & 0.75 & 0.30 & 0.00 & 0.02 & 0.00 & 0.00 & 0.00 & 0.00 & 0.00 & 0.00 & 0.00 \\
- & - & - & - & - & - & - & - & - & - & - & - & - & - & - & - \\
55.0 & 21.0 & 21.0 & 5.50 & 3.30 & 1.15 & 0.70 & 1.00 & 0.08 & 0.35 & 0.35 & 0.30 & 0.10 & 0.01 & 0.01 & 0.00 \\
& & & & & & & & & & & & & 5 & 5
\end{tabular}

The second workpiece material, Ti6Al4V, is typically used in aircraft structural components, turbine blades, discs and rings, weapon structural components, medical implants, fasteners, hand tools, sporting equipment, marine industry, and offshore applications (AZOM, 2002; NeoNickel, 2016). Table 3 show the chemical composition of the Ti64-alloy.

Table 3: Chemical composition of Ti6Al4V (wt.\%)(NeoNickel, 2016)

\begin{tabular}{lllllllllll}
\hline $\mathrm{Ti}$ & $\mathrm{Al}$ & $\mathrm{V}$ & $\mathrm{C}$ & $\mathrm{N}$ & $\mathrm{O}$ & $\mathrm{Fe}$ & $\mathrm{H}$ & $\mathrm{Y}$ & $\begin{array}{l}\text { Others, } \\
\text { each }\end{array}$ & $\begin{array}{l}\text { Others, } \\
\text { total }\end{array}$ \\
\hline Balance & $5.5-6.75$ & $3.5-4.5$ & 0.08 & 0.05 & 0.20 & 0.03 & 0.0125 & 0.005 & 0.1 & 0.4 \\
\hline
\end{tabular}

The wires typically come in $8 \mathrm{~kg}$ spools manufactured by Thermocompact ${ }^{\circledR}$ and are supplied by the machine tool manufacturer itself. Both copper and brass wires were used with $0.25 \mathrm{~mm}$ and $0.30 \mathrm{~mm}$ diameters. 


\subsection{Data collection methods}

Data collection was done at the Manufacturing Technology Centre (MTC), Coventry, UK, which is an industry -university collaborative research facility. Experiments were conducted for five days spanned over three weeks in late 2015 and early 2016. AgieCharmilles® CUT300sp machine was used for the experiments. The machine offered the facility of executing all nine cuts in one go with different parameters.

Supply power was measured using an energy metering device, SPCPro2® data logger. The logger was set to record total power consumption with one second frequency. The device is a loop type, threephase data logger which detects the real time power factor values to calculate the total power. Field notes were used to mark down machining start and finish times as one set of nine cuts were machined in one-go. Figure 2 shows sets of the nine cuts performed in one-go. Each cut was $20 \mathrm{~mm}$ in length.

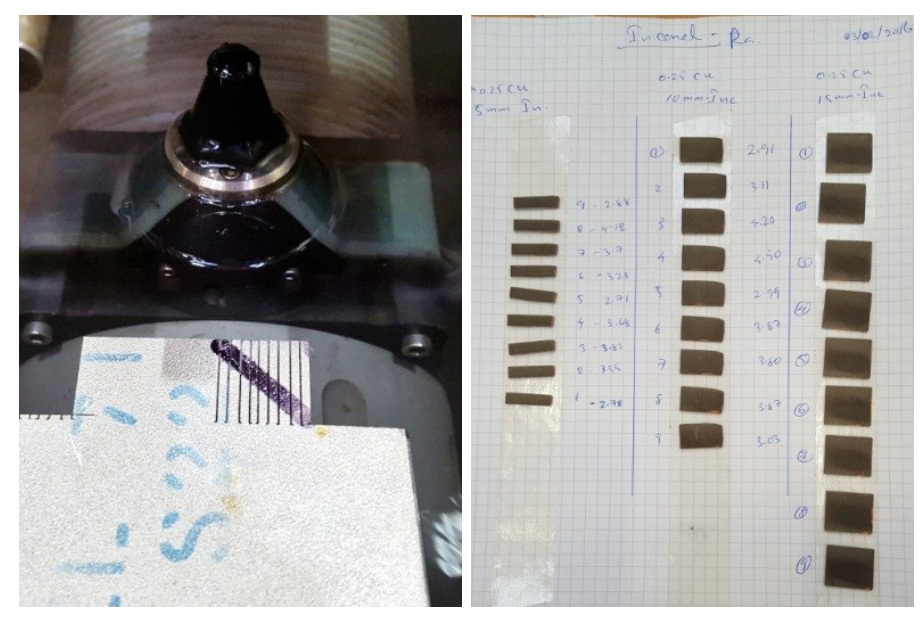

Figure 2: Just finished machine pass of $15 \mathrm{~mm}$ thick Inconel with $0.3 \mathrm{~mm}$ Brass wire (left) and $20 \mathrm{~mm}$ long cut samples of Inconel with thicknesses of 5, 10, and $15 \mathrm{~mm}$ (right)

The area under the power curve was used to calculate the energy consumption per each cut. The removed material volume was calculated using the thickness, wire diameter and the lengths of cut. The logged time records were used to calculate the time taken for each cut. From those data, specific energy consumptions and material removal rates were calculated. Average surface roughness $\left(\mathrm{R}_{\mathrm{a}}\right)$ values were also measured using portable surface roughness meter: Mitutoyo ${ }^{\circ}$ Surftest SJ-210 (measuring range $17.5 \mathrm{~mm}$, detector range $360 \mu \mathrm{m}(-200 \mu \mathrm{m}$ to $+160 \mu \mathrm{m})$, stylus tip radius $5 \mu \mathrm{m})$. $R_{a}$ is a widely used quality indicator of machined surfaces in the industry. Some test pieces were measured in a laboratory bench mounted roughness tester: Taylor-Hobson®-Surtronic-3P (measuring range: 0 $99.99 \mu \mathrm{m}$, accuracy: $\pm 2 \%$, stylus tip radius: $5 \mu \mathrm{m}$ ). An evaluation length of $5 \mathrm{~mm}$ and a cut-off wavelength $\left(\lambda_{c}\right)$ of $0.8 \mathrm{~mm}$ were used with both testers. 


\subsection{Analysis methods}

\subsubsection{Taguchi analysis}

Taguchi method was used to optimise the desired response, specific energy consumption (SEC) and surface roughness. Signal to noise (SN) ratios ( $\eta$ ) are calculated to optimise the desirable output. A signal refers to a desirable output in this case SEC, and a noise refers to an undesirable output such as the standard deviation of the output characteristic. Higher values of SN ratios indicate higher desirable output compared to the undesirable output. Therefore, corresponding input parameters which yield higher SN ratios are selected as optimum parameters. The three scenarios of desirable output are, higher-the-better (HB), lower-the-better (LB), and nominal is better (NB). Equations for the first two scenarios are listed below as the last one was not used for this research.

$$
\begin{aligned}
& \eta_{H B}=-10 \log \left(\frac{1}{n} \sum_{i=1}^{n} \frac{1}{y_{i}^{2}}\right) \\
& \eta_{L B}=-10 \log \left(\frac{1}{n} \sum_{i=1}^{n} y_{i}^{2}\right)
\end{aligned}
$$

Where, $n$ is the number of measurements, and $y_{i}$ is the $i^{\text {th }}$ observation of the desirable output. The analysis was performed using the statistical software Minitab17 ${ }^{\circledR}$.

\subsubsection{Analysis of variance (ANOVA)}

Analysis of variance (ANOVA) tests were performed to identify and prioritise the significant parameters of the process energy consumption. ANOVA is a popular statistical tool which analyses the total variance using two variances: variances within groups and variances between groups. This means the total sum of squares of the standard deviation $\left(\mathrm{SS}_{\mathrm{T}}\right)$ is calculated as the sum of squares within groups $\left(\mathrm{SS}_{\mathrm{W}}\right)$ and the sum of squares between groups $\left(\mathrm{SS}_{\mathrm{BW}}\right)$. The SST is calculated using the following equation.

$$
S S_{T}=\sum_{i=1}^{n}\left(\eta_{i}-\eta_{m}\right)^{2}
$$

Where ' $n$ ' is the number of experiments, ' $\eta_{i}$ ' is the mean SN ratio of the $i^{\text {th }}$ experiment, and $\eta_{\mathrm{m}}$ is the total mean SN ratio. ANOVA calculations were also performed using the Minitab17 ${ }^{\circledR}$.

\section{Process energy analysis}

The logger data were retrieved after every set of cuts to ensure the accuracy and the data security. The data was first viewed with the logger's PC suit software and later exported to MSExcel for analysis. The supply power profile curves were generated after filtering out the non-machining data. Figure 3 shows 
a supply power variation pattern of one of the 24 machining runs. The $x$-axis shows the real time of the experiments.

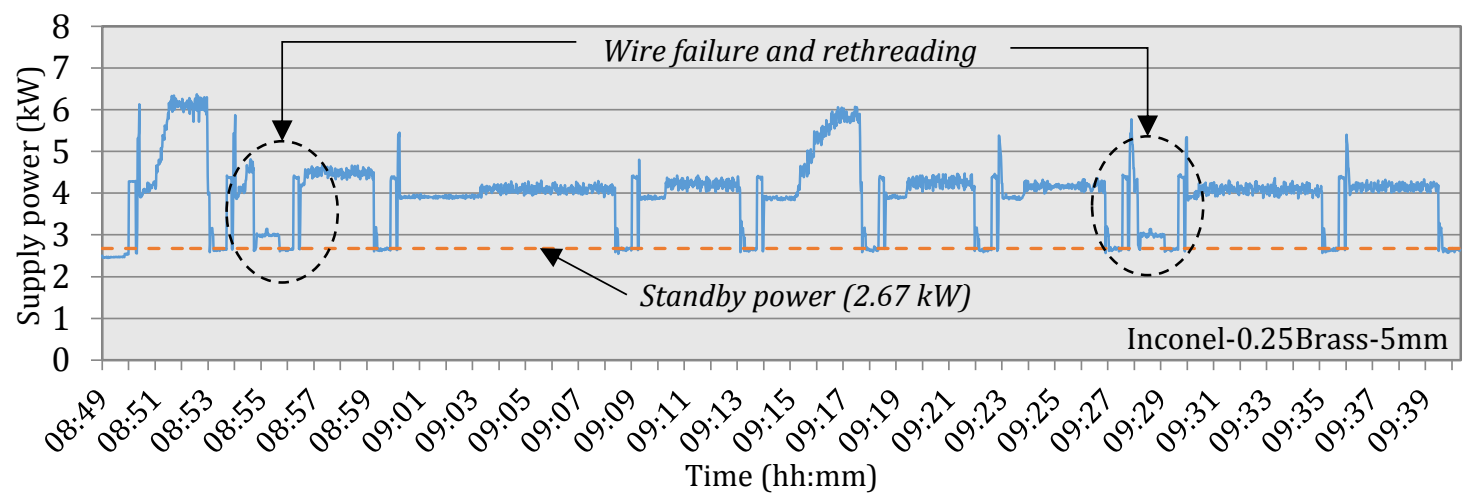

Figure 3: Sample supply power profile for WEDM of $5 \mathrm{~mm}$ thick Inconel-718 with $0.25 \mathrm{~mm}$ brass wire In total, 216 cuts were made with a length of $20 \mathrm{~mm}$ each. Each wave of Figure 3 corresponds to a cut made with one of the nine combinations suggested by the L9 orthogonal array. In the order of events, a given wave includes wire threading, tool positioning, tank filling, machining, and automatic wire separation. The pattern of each wave is mostly similar with different machining times which indicate the changes in the energy consumption. The standby power averages to $2.67 \pm 0.02 \mathrm{~kW}$ considering all 24 sets of cuts of both metals as shown with a dotted line in Figure 3. The narrower variation implies that the standby power is less dependent on the workpiece type/thicknesses or wire types.

Another observation from Figure 3 is that each nine-cut set takes about 35-50 minutes to cut with single-pass programming. The wave profiles show different shapes which indicate the influence of changes in discharge parameters. The peak power consumption and cutting duration, which determine the specific energy, vary from case to case. In some cases, as shown Figure 3, wire failures were observed. This causes a drop in power and additional automatic rethreading run before catching up with the machining. The power profiles for the remaining 23 sets of cuts are not presented here but a summary of results is included in section 5 .

Energy consumed per cut was determined by filtering the power levels above the standby power and individually identifying the boundaries of starting and finishing times. The volume of material removed per cut was estimated considering the cut dimensions and the wire diameter. Machining time per cut was calculated using the data logger time records. These values are then used to calculate the SEC and MRR values. Figure 4 shows the variations of SEC (primary y-axis) and $\mathrm{R}_{\mathrm{a}}$ (secondary y-axis) for a sample experiment of Inconel machining with $0.25 \mathrm{~mm}$ brass wire. 


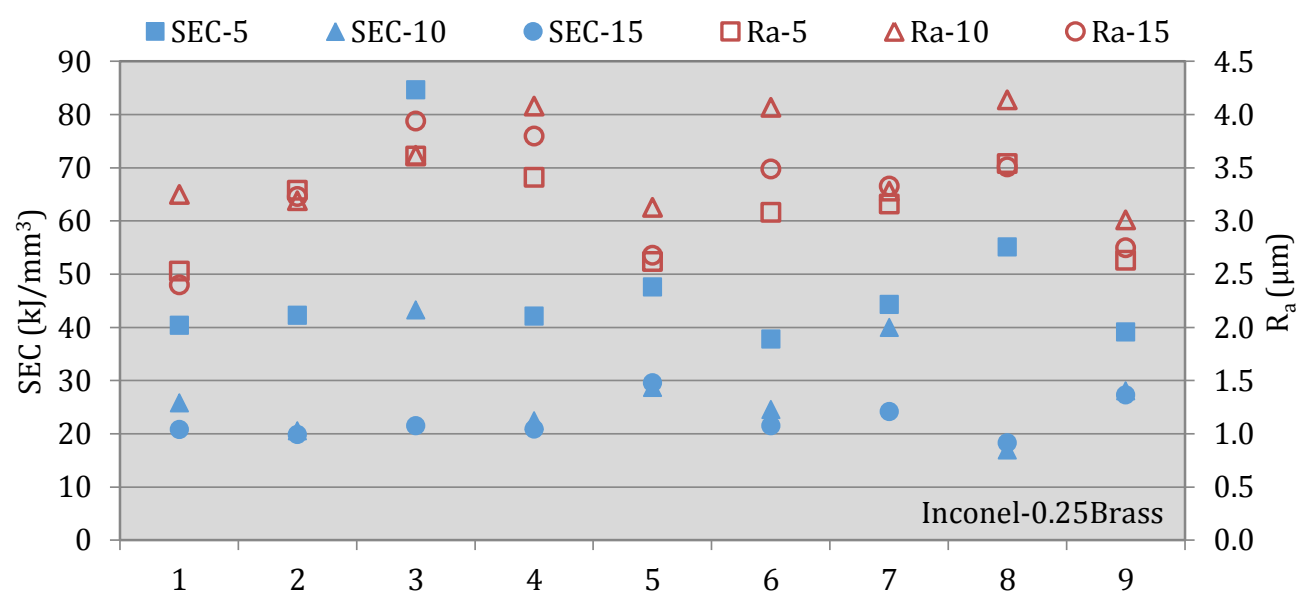

Figure 4: SEC and $\mathrm{R}_{\mathrm{a}}$ results for WEDM of Inconel-718 (5, 10, and $15 \mathrm{~mm}$ thick) with $0.25 \mathrm{~mm}$ brass wire

Initially, it was observed that the energy consumption of experiments with brass wires was higher than that with copper wire. Secondly, the SEC for $5 \mathrm{~mm}$ thick cuts (SEC-5) is high with a wider margin compared to 10 and $15 \mathrm{~mm}$ cuts for all cases. This can be attributed to the influence of lower material volume removed with $5 \mathrm{~mm}$ thick workpieces. The absolute energy consumption per each cut is the highest with $15 \mathrm{~mm}$ thick workpieces and the least for $5 \mathrm{~mm}$ thick workpieces. The SEC data points for each workpiece thickness run parallel to a greater extent indicating that the parameter combinations influence SEC in a similar manner even with different workpiece thicknesses and wire types. The lowest SEC values appear to be with $2^{\text {nd }}$ and $8^{\text {th }}$ experiments in almost all cases. The $R_{a}$ variation, as shown in the secondary axes of Figure 4, which is common for most of the case, indicates the lowest surface roughness values result with $1^{\text {st }}, 5^{\text {th }}$, and $9^{\text {th }}$ experiments. Among these three different parameter combinations, the only common factor is the lower (or level-1 of) pulse-ON time (refer to Table 4).

As with Inconel, WEDM of Ti6Al4V with brass wires also seems to consume more energy than copper wire. Out of all the experiments, the most number of wire failures were observed with Ti64-alloy cutting with copper wire. It was observed that the lowest SEC is achieved in $4^{\text {th }}, 6^{\text {th }}$, and $8^{\text {th }}$ cuts in most of the cases; however, no commonalities can be seen in terms of discharge parameters. As observed with Inconel experiments, the surface roughness with Ti64-alloy experiments also follows the same pattern as observed with Inconel with most cases. This indicates that $1^{\text {st }}, 5^{\text {th }}$, and $9^{\text {th }}$ cuts have fine surface finishes than other experiments. However, for all cases, the $\mathrm{R}_{\mathrm{a}}$ value ranges from 2.000 to $4.000 \mu \mathrm{m}$. It should be noted that $\mathrm{R}_{\mathrm{a}}$ was measured to optimise WEDM for both SEC and $\mathrm{R}_{\mathrm{a}}$, as it will be pointless to optimise only for SEC at the expense of surface quality.

\section{Sustainability implications of standby energy}

\subsection{Energy saving potential with sensible operating practices}

It is typical to leave the machines on standby overnight and over the weekends to save the shutting down and starting up times and efforts. Within this case study, the main machine unit and the chiller 
(Model: TAEevo® - water cooled) were separately powered and the standby power demand was monitored. The machine unit (excluding the chiller) consumed an average standby power of $2.47 \mathrm{~kW}$ based on three nights' data. The chiller is triggered automatically during the night to keep the water at the set temperature $\left(17 \pm 5^{\circ} \mathrm{C}\right)$ to supply on demand dielectric. This may vary based on the make of the machine and underline algorithms. For example, standby powers of $5.6 \mathrm{~kW}$ (ready to machine) and 3.7 kW (hibernated/sleep mode) have been reported with another model of WEDM machine in Gamage and DeSilva, (2016). Figure 5 shows the overnight power consumption of a chiller, where it can be seen that, roughly for every 20 minutes, the chiller was working approximately 2.5 minutes. The duration and the frequency of triggering the chiller are based on the ambient temperature, which is affected by many factors such as building insulation, heat load from other machines, and the season of the year (summer/ winter). This data corresponds to October 2015 with mean temperatures of $14.4{ }^{\circ} \mathrm{C}$ ( $\max )$ to $7.1^{\circ} \mathrm{C}(\mathrm{min})$ in England (MET OFFICE, 2016). With three nights' data, the average power consumption for the chiller was calculated as $0.82 \mathrm{~kW}$. Hence, the total non-working power consumption for both the machine and the chiller is $3.3 \mathrm{~kW}$.

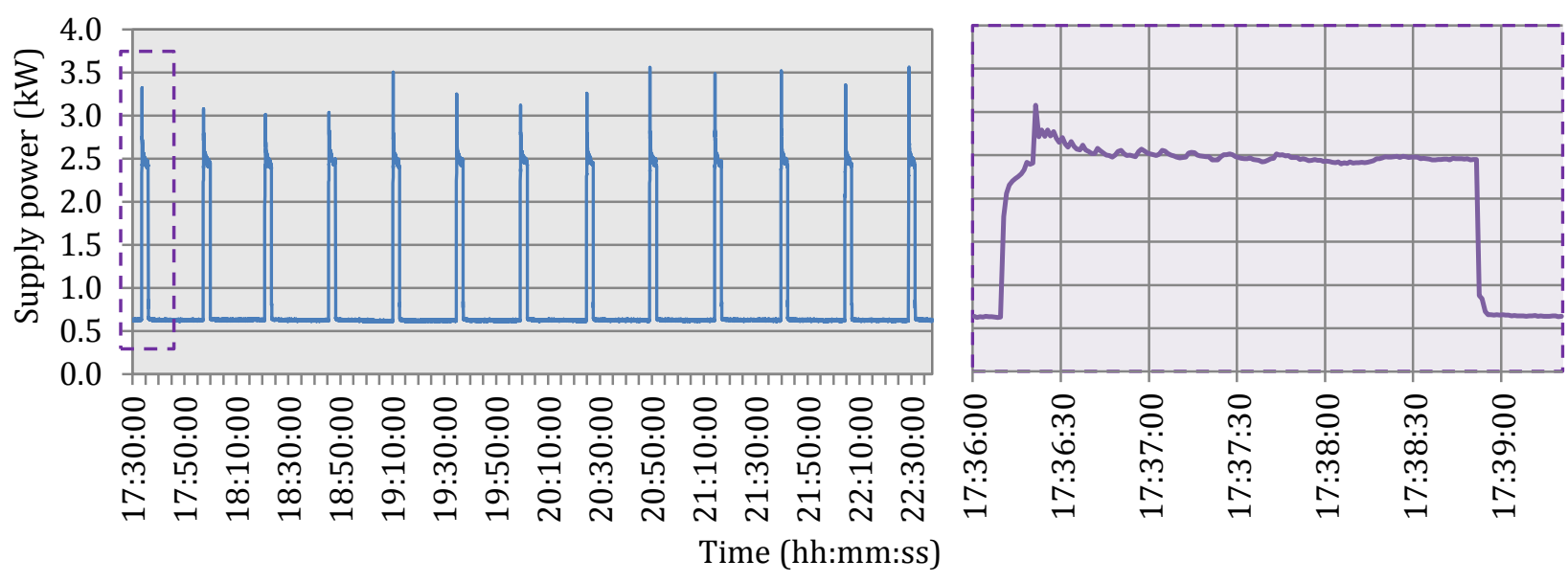

Figure 5: Overnight power consumption of the water chiller (left) and the enlarged view of the encircled first triggering after 17:30:00 (right)

Based on 8-hour shift a day, 260 working days a year (Jones, 2017), and 105 non-working days, the total non-working time is calculated as 6,680 hours a year during which the machines assumed to be left on standby. Thus the total potential energy saving is calculated as 22,009 kWh (79,232 MJ). With an energy price of 9.36 pence per kWh, the average for a medium-sized UK company in 2015 (DEPARTMENT FOR BUSINESS, ENERGY \& INDUSTRIAL STRATEGY, 2016), the annual savings on electrical energy would be $€ 2,060$. Thus, three such machines would mean a saving of $€ 6,180$ a year. It should be noted that any implications of shutting down and restarting the machines on process energy, health and safety, and operational procedures were ignored in this analysis. The relative energy saving depends on the degree of utilisation of the machines during working hours. Based on 8 hours shift a day, neglecting the intermittent standby times due to operator resting and changeovers, the total machining hours per year would be 2060 hours per machine. The average machining power, including the chiller, as observed during the study period is $6.45 \mathrm{~kW}$ (with a standard deviation of 0.6 
$\mathrm{kW})$. This amounts to a working time energy consumption of 13,416 kWh (48,298 MJ) per year. Figure 6 shows the composition of energy consumption during a year for one machine.

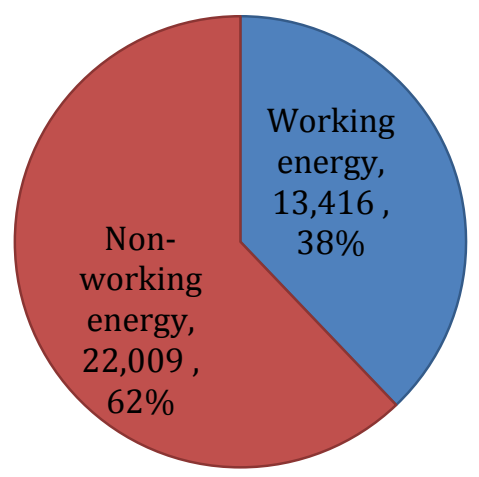

Figure 6: Relative energy consumption (kWh/yr) during working and non-working times It can be seen that $62 \%$ of the total energy is consumed during non-working hours to keep the machine on standby. This means over $2 / 3^{\text {rd }}$ of the total energy consumed can potentially be saved. However, it should be investigated that the implications of shutting down and restarting machines in terms of energy and cost savings. New mechanisms (technologies and/or operating practices) could thus be implemented to harness this potential to reduce the burden on the environment and reduce the financial costs of operation.

\subsection{Environmental impact}

The potential energy saving can be viewed in terms of reduction in carbon emissions. Based on the World Research Institute (WRI)/ World Business Council for Sustainable Development (WBCSD)(WRI, 2011) Greenhouse Gas Protocol (GHGP)(GHGPROTOCOL, 2017), the total carbon emissions from the electrical energy used by one WEDM machine is calculated as 23.57 tonnes of $\mathrm{CO}_{2}$ eq. This means the emissions from the non-working energy per year is 14.64 tonnes of $\mathrm{CO}_{2}$ eq which is $62 \%$ of the total emissions. Therefore, it is theoretically possible to save up to 14.64 tonnes of $\mathrm{CO}_{2}$ eq per year from one WEDM machine. A machining shop with multiple machines could mean substantial savings. Figure 7 shows the composition of the equivalent of carbon emissions from the electrical energy consumed. The Great Britain (GB) dataset of ecoinvent version 3.3 database for medium voltage (1 kV to $24 \mathrm{kV}$ ) electricity was used for the analysis. 


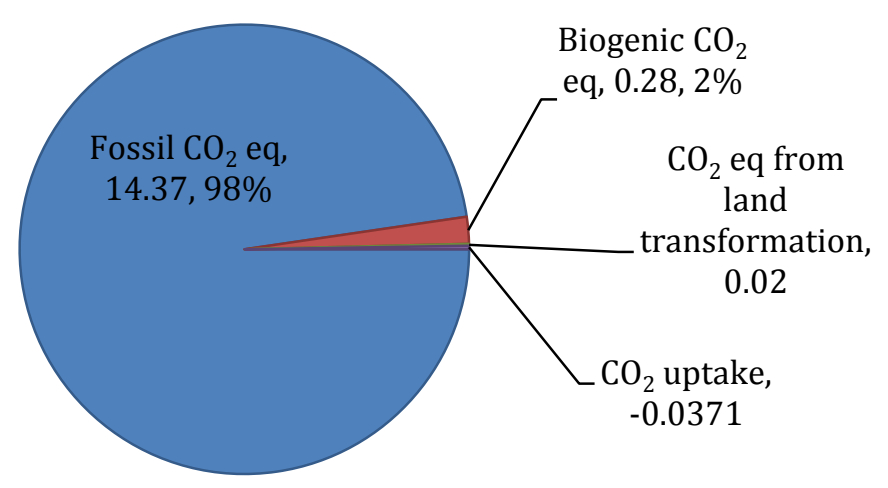

Figure 7: Carbon footprint of electrical energy consumed for keeping WEDM machine and the chiller on standby during non-working hours a year in tonnes of $\mathrm{CO}_{2}$ equivalents [Analysis method: Greenhouse Gas Protocol V1.01, LCA software: SimaPRO8]

It can be seen that $98 \%$ of the carbon are based on fossil fuels and the balance is from biogenic sources and land transformation. The carbon emissions of electrical power generation depend on the way each country source their energy. In 2014, 62\% of the UK's electrical power generation was sourced from fossil resources (Carbonbrief, 2015). Carbon uptake refers to the carbon stored in plants and trees as they grow. Therefore, sensible operating procedures and technology developments to plan smart shutting down and restarting of machines and subunits would mean significant economic and environmental savings.

In relation to sustainable machining technologies, Pusavec et al. (2010) have reported cryogenic and high-pressure jet assisted machining are more sustainable compared to the flood cooling in conventional machining considering the overall life cycle of the cooling/lubrication fluid. In terms of the sustainable unconventional machining, Kellens et al. (2011) and Gamage et al. (2016) have presented the environmental performance analysis of electrodischarge machining considering the overall unit process impact of energy, resources, and emissions.

\section{Results and discussion}

\subsection{Results - Taguchi analysis}

Signal to noise (SN) ratios were calculated optimising for lower-the-better SEC and Ra. Table 4 summarises the $\mathrm{SN}$ ratios for each parameter combination for each case. In the table, $\mathrm{SN}-5, \mathrm{SN}-10$, and SN-15 refer to the SN ratios for 5, 10, and $15 \mathrm{~mm}$ thick workpieces respectively. Parameter levels are indicated as 1,2, and 3. The higher SN ratios indicate the better/optimum output characteristics which are, lower-the-better SEC and lower-the-better surface roughness. Hence, the top three SN ratios are indicated with bold characters to identify patterns. It can be seen that the $2^{\text {nd }}$ and $8^{\text {th }}$ experiments of Inconel have produced the highest SN ratios in 9 out of 12 instances. The parameter combinations are 1-2-2-2 and 3-2-1-3 for voltage, peak current, pulse-OFF, and pulse-ON respectively. For Ti64 alloy, the highest SN ratios resulted for the $4^{\text {th }} 6^{\text {th }}$, and $8^{\text {th }}$ experiments in 9 out of 12 cases. 
The $0.25 \mathrm{~mm}$ diameter wires yielded consistent results. The corresponding parameter combinations are 2-1-2-3, 2-3-1-2, and 3-2-1-3. These results are consistent with the SEC analysis (section 3). The mean $\mathrm{SN}$ ratios against the parameter level were plotted to see the significance of the variations and identify the interrelations.

The main effects plots (Figure 8 and Figure 9 show a sample from $5 \mathrm{~mm}$ thick workpieces) were generated to analyse the optimum levels of each parameter with Table 5 summarising an assessment of all 24 cases. It can be seen from Figure 8, that the most sensitive parameters for Inconel are the voltage and the pulse-OFF time. It can be concluded that lower (Level-1) of P-OFF and higher (Level-3) of voltage are better for minimising SEC and $\mathrm{R}_{\mathrm{a}}$. The only exception is the $0.25 \mathrm{~mm}$ brass wire case which suggests moderate (Level-2) voltage is better.

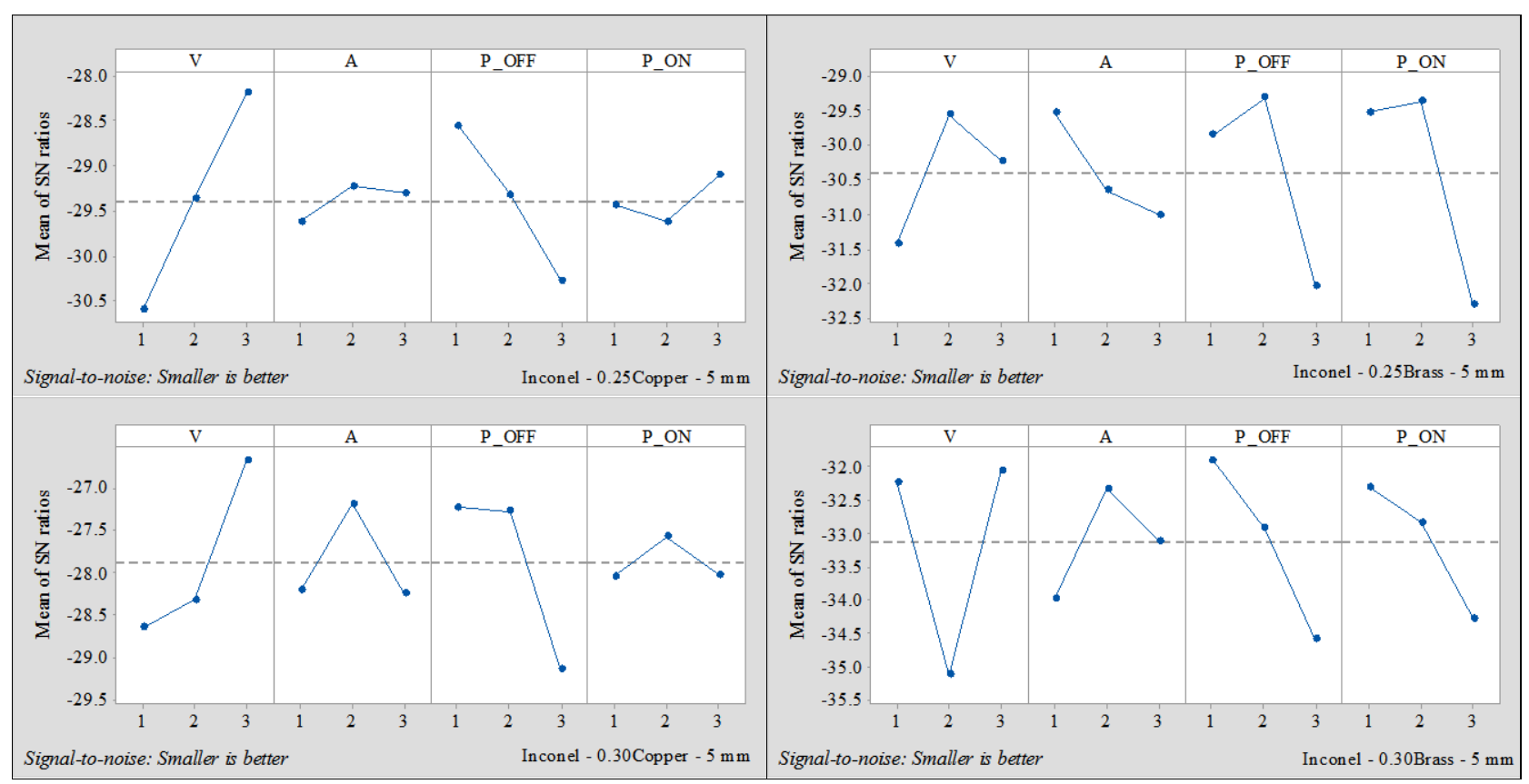

Figure 8: Main effects plots of $5 \mathrm{~mm}$ cases - Inconel-718 
Table 4: SN ratios for lower-the-better SEC and $\mathrm{R}_{\mathrm{a}}$ with top three SN ratios in bold (SN-5, SN-10, and SN-15 refer to the SN ratios for 5, 10 , and 15 mm thick workpieces respectively)

\begin{tabular}{|c|c|c|c|c|c|c|c|c|c|c|c|c|c|c|c|c|c|}
\hline & \multirow{2}{*}{$\begin{array}{l}\text { Ex } \\
\#\end{array}$} & \multicolumn{2}{|c|}{ Parameters } & \multirow[b]{2}{*}{ P-OFF } & \multirow[b]{2}{*}{$\mathrm{P}-\mathrm{ON}$} & \multicolumn{3}{|c|}{$0.25 \mathrm{~mm}$ copper wire } & \multicolumn{3}{|c|}{$0.25 \mathrm{~mm}$ brass wire } & \multicolumn{3}{|c|}{$0.30 \mathrm{~mm}$ copper wire } & \multicolumn{3}{|c|}{$0.30 \mathrm{~mm}$ brass wire } \\
\hline & & $\mathrm{V}$ & A & & & SN-5 & SN-10 & SN-15 & SN-5 & SN-10 & SN-15 & SN-5 & SN-10 & SN-15 & $\mathrm{SN}-5$ & SN-10 & SN-15 \\
\hline \multirow{9}{*}{ 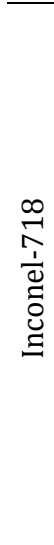 } & 1 & 1 & 1 & 1 & 1 & -30.06 & -22.41 & -22.23 & -29.13 & -25.30 & -23.40 & -28.48 & -22.32 & -21.04 & -30.99 & -26.28 & -23.40 \\
\hline & 2 & 1 & 2 & 2 & 2 & -30.60 & -21.72 & -20.39 & -29.54 & -23.36 & -23.07 & -27.04 & -20.60 & -18.89 & -30.90 & -25.12 & -23.00 \\
\hline & 3 & 1 & 3 & 3 & 3 & -31.13 & -24.53 & -22.45 & -35.55 & -29.75 & -23.79 & -30.41 & -23.75 & -21.05 & -34.80 & -28.89 & -26.10 \\
\hline & 4 & 2 & 1 & 2 & 3 & -29.26 & -25.19 & -21.41 & -29.52 & -24.17 & -23.54 & -28.19 & -22.50 & -19.58 & -36.87 & -28.21 & -26.10 \\
\hline & 5 & 2 & 2 & 3 & 1 & -30.14 & -25.72 & -24.35 & -30.56 & -26.21 & -26.45 & -29.05 & -25.11 & -23.07 & -34.93 & -29.17 & -26.85 \\
\hline & 6 & 2 & 3 & 1 & 2 & -28.69 & -23.06 & -21.38 & -28.57 & -24.91 & -23.77 & -27.72 & -22.79 & -21.95 & -33.54 & -27.55 & -23.84 \\
\hline & 7 & 3 & 1 & 3 & 2 & -29.55 & -24.19 & -22.36 & -29.94 & -29.06 & -24.75 & -27.96 & -22.90 & -21.23 & -34.02 & -27.97 & -25.23 \\
\hline & 8 & 3 & 2 & 1 & 3 & -26.93 & -21.12 & -18.35 & -31.84 & -21.85 & -22.41 & -25.46 & -19.59 & -17.16 & -31.14 & -25.07 & -21.57 \\
\hline & 9 & 3 & 3 & 2 & 1 & -28.10 & -22.98 & -22.27 & -28.87 & -26.02 & -25.77 & -26.59 & -21.97 & -20.08 & -30.97 & -25.16 & -23.01 \\
\hline \multirow{9}{*}{ 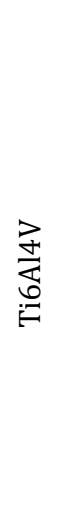 } & 1 & 1 & 1 & 1 & 1 & -29.47 & -25.41 & -22.50 & -32.31 & -31.65 & -31.81 & -30.41 & -29.36 & -21.21 & -26.66 & -25.32 & -24.32 \\
\hline & 2 & 1 & 2 & 2 & 2 & -27.52 & -25.62 & -22.80 & -31.65 & -31.86 & -32.63 & -28.97 & -18.92 & -19.26 & -27.54 & -24.75 & -23.72 \\
\hline & 3 & 1 & 3 & 3 & 3 & -27.77 & -24.92 & -24.63 & -36.45 & -33.67 & -33.68 & -29.51 & -21.81 & -18.79 & -31.74 & -24.74 & -24.61 \\
\hline & 4 & 2 & 1 & 2 & 3 & -26.20 & -22.24 & -21.64 & -28.42 & -26.77 & -27.24 & -19.46 & -24.71 & -17.82 & -29.15 & -23.82 & -22.06 \\
\hline & 5 & 2 & 2 & 3 & 1 & -32.13 & -30.44 & -28.70 & -37.77 & -38.20 & -38.82 & -23.96 & -21.20 & -21.98 & -25.49 & -28.72 & -25.60 \\
\hline & 6 & 2 & 3 & 1 & 2 & -26.14 & -21.20 & -21.33 & -28.05 & -26.65 & -26.21 & -21.01 & -23.60 & -18.52 & -27.35 & -24.03 & -22.21 \\
\hline & 7 & 3 & 1 & 3 & 2 & -28.17 & -24.90 & -24.54 & -32.45 & -32.40 & -33.09 & -21.41 & -22.75 & -19.55 & -32.15 & -24.25 & -23.43 \\
\hline & 8 & 3 & 2 & 1 & 3 & -26.13 & -21.12 & -20.75 & -27.71 & -25.65 & -25.36 & -19.92 & -27.48 & -17.27 & -26.32 & -27.88 & -21.81 \\
\hline & 9 & 3 & 3 & 2 & 1 & -29.08 & -26.30 & -24.33 & -33.75 & -33.67 & -34.32 & -23.22 & -21.79 & -20.65 & -30.42 & -27.92 & -23.74 \\
\hline
\end{tabular}


From Figure 9 it can be seen that the results for Ti64-alloy are not as clear as that for Inconel. For cases with $0.25 \mathrm{~mm}$ wires, the most influencing parameters are the pulse times. However, for the 0.30 $\mathrm{mm}$ wires, the results are inconclusive. The experiments with $0.25 \mathrm{~mm}$ brass or copper wires show that lower P-OFF (Level-1) and higher (Level-3) P-ON times are better for achieving the required characteristics.

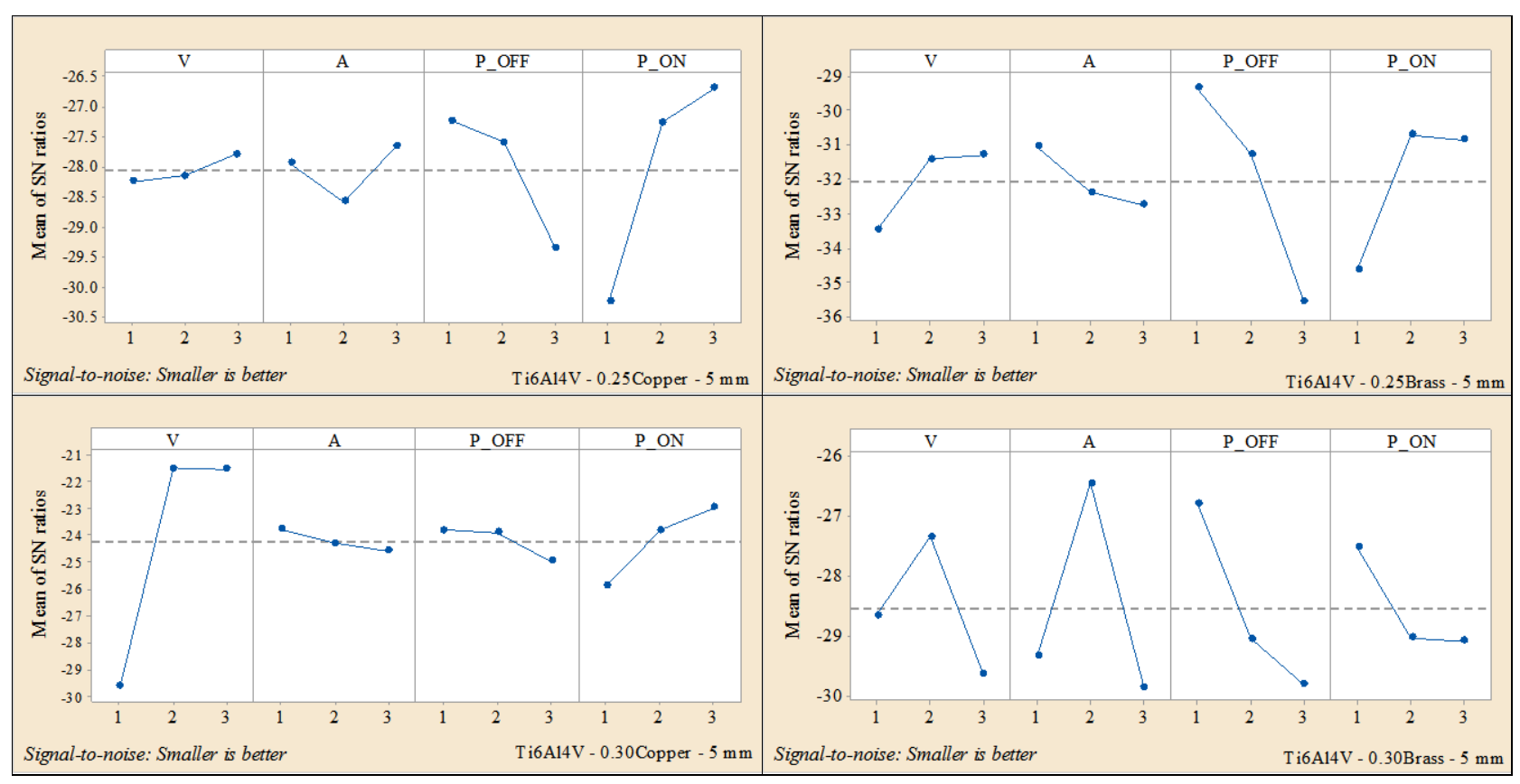

Figure 9: Main effects plots of $5 \mathrm{~mm}$ cases - Ti6Al4V

Table 5 shows the assessment of all (24) the main effects plots. The last column of the table indicates the most sensitive input parameters for the response characteristics SEC and $\mathrm{R}_{\mathrm{a}}$. The ' $\uparrow$ ' denotes higher (Level-3) is better, ' $\downarrow$ ' denotes lower (Level-1) is better, or ' $\uparrow$ ' denotes moderate (Level-2) level is better for lower-the-better SEC and $\mathrm{R}_{\mathrm{a}}$. For machining Ti64-alloy with $0.30 \mathrm{~mm}$ wire, the mean SN ratio variation is fuzzy. In conclusion, it can be seen from Table 5 that except for $0.30 \mathrm{~mm}$ wires with Ti64-alloy, the results are conclusive for all the other cases.

Table 5: Conclusions from Taguchi analysis

\begin{tabular}{llll}
\hline Workpiece & Wire diameter & Wire material & For lower SEC \& $\mathrm{R}_{\mathrm{a}}$ \\
\hline \multirow{2}{*}{ Inconel-718 } & $0.25 \mathrm{~mm}$ & Copper & P-OFF $\downarrow-\mathrm{V} \uparrow$ \\
\cline { 2 - 4 } & $0.30 \mathrm{~mm}$ & Brass & P-OFF $\downarrow-\mathrm{V} \uparrow$ \\
\hline \multirow{2}{*}{ Ti6Al4V } & Copper & P-OFF $\downarrow-\mathrm{V} \uparrow$ \\
& $0.25 \mathrm{~mm}$ & Brass & P-OFF $\downarrow-\mathrm{V} \uparrow$ \\
\cline { 2 - 4 } & & Copper & P-OFF $\downarrow-\mathrm{P}-\mathrm{ON} \uparrow$ \\
& & Brass & P-OFF $\downarrow-\mathrm{P}-\mathrm{ON} \uparrow$ \\
\hline
\end{tabular}




\subsection{Results - ANOVA}

ANOVA tests were performed to analyse the relative significance of all input parameters towards selected response characteristic. The general linear model of ANOVA is used as it suits better in the context of multi-parameter optimisation. A significant parameter is identified if the p-value is less than $0.05(\mathrm{p}<0.05)$ which indicates 95\% confidence level. Table 6 shows the ANOVA table considering the response characteristic as SEC. The columns show, the source parameters, the degrees of freedom (number of levels less 1), the adjusted sum of squares, the adjusted mean sum of squares (AdjSS/DF), F-value (AdjMS/mean squared error), the probability value, and the percentage contribution (SS for each factor/total SS) respectively.

The significant factors $(\mathrm{p}<0.05)$ are presented in bold characters in the table. There are 8 sources/factors with 216 resultant data points. This has caused relatively larger error term. However, the order of significance of factors remains unaffected. As can be seen from Table 6, five-factors are significantly affecting the SEC of WEDM. In the order of relative contribution, these are: workpiece thickness, wire material, pulse-OFF time, wire diameter, and pulse-ON time.

Table 6: ANOVA results for SEC

\begin{tabular}{lllllll}
\hline Source & DF & Adj SS & Adj MS & F-Value & P-Value & \% contribution \\
\hline Workpiece material & 1 & 608.2 & 608.2 & 3.2 & 0.074 & $0.76 \%$ \\
Wire material & 1 & $13,802.1$ & $13,802.1$ & 73.3 & $\mathbf{0 . 0 0 0}$ & $\mathbf{1 7 . 1 9 \%}$ \\
Wire diameter & 1 & $3,755.4$ & $3,755.4$ & 19.9 & $\mathbf{0 . 0 0 0}$ & $\mathbf{4 . 6 8 \%}$ \\
Workpiece thickness & 2 & $15,826.1$ & $7,913.0$ & 42.0 & $\mathbf{0 . 0 0 0}$ & $\mathbf{1 9 . 7 1 \%}$ \\
Voltage & 2 & 604.5 & 302.3 & 1.6 & 0.203 & $0.75 \%$ \\
Peak current & 2 & 70.3 & 35.2 & 0.2 & 0.830 & $0.09 \%$ \\
Pulse-OFF time & 2 & $5,658.2$ & $2,829.1$ & 15.0 & $\mathbf{0 . 0 0 0}$ & $\mathbf{7 . 0 5 \%}$ \\
Pulse-ON time & 2 & $1,938.3$ & 969.1 & 5.2 & $\mathbf{0 . 0 0 7}$ & $\mathbf{2 . 4 1 \%}$ \\
Error & 202 & $38,035.0$ & 188.3 & & & $47.37 \%$ \\
Total & 215 & $80,298.2$ & & & & \\
\hline
\end{tabular}

Figure 10 shows the standardised residual plots for the response characteristic (SEC). A residual in the ANOVA-general linear model refers to a deviation from the observed value from the fitted values of the model. The normal probability plot (Figure 10 -upper left) shows a majority of the data points follow roughly a straight line. However, about five points out of the total 216 points fall away from the line indicating large residuals. This does not seem to provide sufficient evidence of non-normality. The upper right graph shows the residuals versus fitted values. Most of the residuals are randomly scattered closer to the zero (the dotted line) despite the evidence of few outliers. 

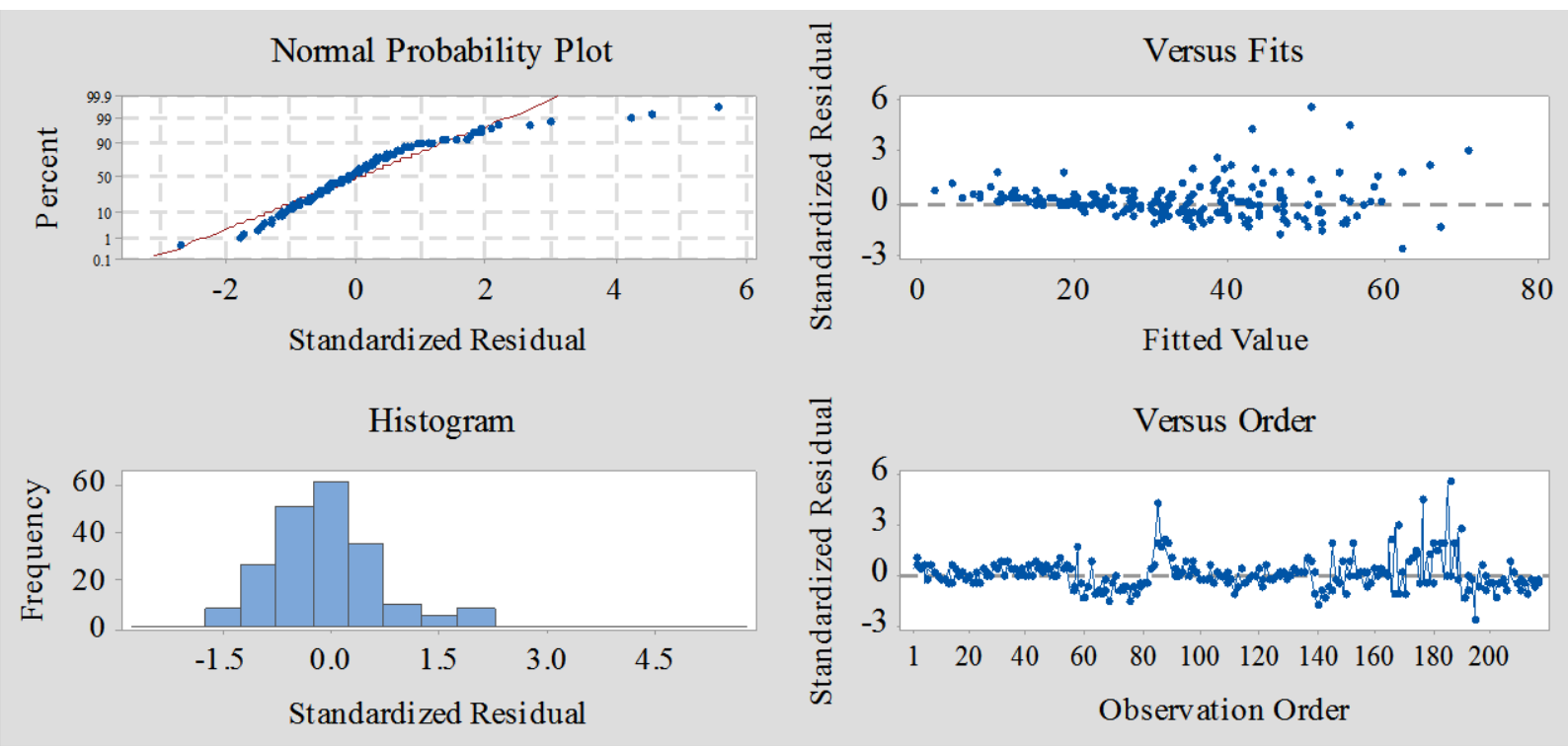

Figure 10: ANOVA residual plots for specific energy consumption

The histogram (Figure 10-lower left) shows the distribution of the residuals of all 216 observations.

Slight skewness can be observed towards the right. However, the narrower spread, mostly within \pm 1.5 , indicates magnitudes of the residuals are minor except for few extreme cases. The histogram tallies with the information of the other plots. The last plot shows the residuals in the order of observation. Most residuals show minor variations apart from the outliers observed towards latter experiments. The corresponding experiments were traced as $85^{\text {th }}, 87^{\text {th }}, 165^{\text {th }}, 167^{\text {th }}, 176^{\text {th }}, 185^{\text {th }}, 189^{\text {th }}$, and $194^{\text {th }}$ experiment. Apart from the first couple, the rest of the outliers are observed with machining Ti6A alloy (all thicknesses) with brass wire (mostly $0.25 \mathrm{~mm}$ wire). No outliers correspond to experiments with copper wires. ANOVA is continued to other two response parameters, MRR and $R_{a}$, although the individual tables are not presented as the main objective of the research is to optimise for energy. Table 7 summarises the percentage contributions from each factor to the response characteristics.

Table 7: Summary of contributions from each factor to response variables

\begin{tabular}{llll}
\hline Source & SEC & MRR & Ra \\
\hline Workpiece material & $0.8 \%$ & $0.1 \%$ & $\mathbf{2 1 . 5 \%}$ \\
Wire material & $\mathbf{1 7 . 2 \%}$ & $\mathbf{1 4 . 1 \%}$ & $\mathbf{1 . 5 \%}$ \\
Wire diameter & $\mathbf{4 . 7 \%}$ & $\mathbf{5 . 2 \%}$ & $\mathbf{4 . 2 \%}$ \\
Workpiece thickness & $\mathbf{1 9 . 7 \%}$ & $\mathbf{4 1 . 4 \%}$ & $0.4 \%$ \\
Voltage & $0.8 \%$ & $0.6 \%$ & $0.4 \%$ \\
Peak current & $0.1 \%$ & $0.7 \%$ & $1.0 \%$ \\
Pulse-OFF time & $\mathbf{7 . 0 \%}$ & $\mathbf{4 . 4 \%}$ & $0.1 \%$ \\
Pulse-ON time & $2.4 \%$ & $1.9 \%$ & $\mathbf{3 4 . 4 \%}$ \\
Error & $47.4 \%$ & $31.5 \%$ & $36.5 \%$ \\
\hline
\end{tabular}




\section{Conclusions}

The research aimed at assessing the main contributor of the environmental impact of EDM unit processes found it to be the electrical energy. WEDM of two superalloys, Inconel-718 and Ti6Al4V, were tested for eight variables namely, workpiece material, workpiece thickness, wire material, wire diameter, and four discharge parameters: gap voltage, peak current, pulse-ON time, and pulse-OFF time. Taguchi analysis and ANOVA tests were performed to optimise the specific energy consumption and surface roughness. Experiments for 216 combinations of parameters were analysed.

Considering the discharge parameters, it can be concluded that, lower pulse-OFF times and higher voltage values yield lower SEC and $\mathrm{R}_{\mathrm{a}}$ for machining of Inconel. For Ti64-alloy also, lower pulse-OFF time is preferred with higher pulse-ON times for the same optimisation criteria. However, ANOVA with all eight variables suggests that, in the order of importance, workpiece thickness, wire material, wire diameter, and pulse-OFF time as the most significant parameters for minimising the specific energy consumption. Same factors are significant for achieving higher MRR. Most of the outlier results were corresponding to machining of Ti64-alloy with brass wire and no outliers were related to experiments with copper wire. The factors were also analysed for finer surface finishes by optimising for lower $R_{a}$. The ANOVA results have shown that pulse-ON time, workpiece material, wire diameter, and wire material as the significant parameters for lower $R_{a}$. It should be noted that all the experiments were programmed as rough cuts to avoid complications of tracing the effects of set discharge parameters in the event of automatic shifting to finishing-cut parameters. Furthermore, $62 \%$ of the total energy consumption was found to correspond to non-working energy of the machine which can potentially be saved with appropriate measures.

The recommendations to the decision makers with operational and strategic level responsibilities in order to improve the sustainability of their operations are as follows. As the standby power of the machine causes a significant influence on the process energy consumption of EDM, the managers can revisit their operating practices with regard to shutting down of the machines and subunits (e.g. chillers) during non-working hours (nights and weekends). This could potentially save up to $62 \%$ of the total energy, and thus reduce the environmental impact and expenses. In terms of strategic improvements, they may consider investing in modern or smart machining technologies. Modern EDM machines are automated to a greater extent with minimum operator dependency which indirectly reduces the resource consumption. However, specific focus on environmental concerns related to energy consumed, resources used, and emissions are still hardly accounted for. Therefore, it can be suggested to invest in machinery upgrade and smart machining systems (SMS). SMS could provide the optimum solution for the part being machined in terms of production time, cost, and environmental impact. If the available technological solutions are implemented, combined with intelligent optimisation methods, it is estimated that a potential reduction of at least $50 \%$ can be achieved in manufacturing energy. 
Further research could be directed towards automated or smart energy data monitoring and reporting system to account for energy and other resources. These data can then be used by machine tool manufacturers to integrate the technology to reap the savings during both non-machining and machining times.

\section{Acknowledgement}

Authors would like to acknowledge the postgraduate project support funding from RADMA association towards case study related expenses and Glasgow Caledonian University for its PhD studentship towards this research. Furthermore, the authors highly appreciate the support from the Manufacturing Technology Centre (MTC), Coventry, UK for facilitating state-of-the-art machining facility and consumables towards this research. Authors especially acknowledge Mr Phillip Hayward, Advanced Research Engineer at MTC for his support with the experimentation process.

\section{References}

AZOM, 2002. Titanium Alloys - Ti6Al4V Grade 5 [WWW Document]. URL http://www.azom.com/article.aspx?ArticleID=1547 (accessed 12.7.16).

Carbonbrief, 2015. Mapped: How the UK generates its electricity [WWW Document]. Carbon Brief. URL https://www.carbonbrief.org/mapped-how-the-uk-generates-its-electricity (accessed 7.11.16).

DEPARTMENT FOR BUSINESS, ENERGY \& INDUSTRIAL STRATEGY, 2016. International industrial energy prices - GOV.UK [WWW Document]. URL https://www.gov.uk/government/statisticaldata-sets/international-industrial-energy-prices (accessed 12.19.16).

Dhanik, S., Xirouchakis, P., Perez, R., 2011. A System for Resource Efficient Process Planning for Wire EDM, in: Hesselbach, J., Herrmann, C. (Eds.), Glocalized Solutions for Sustainability in Manufacturing. Springer Berlin Heidelberg, pp. 219-224.

Duflou, J.R., Sutherland, J.W., Dornfeld, D., Herrmann, C., Jeswiet, J., Kara, S., Hauschild, M., Kellens, K., 2012. Towards energy and resource efficient manufacturing: A processes and systems approach. CIRP Ann. - Manuf. Technol. 61, 587-609. doi:10.1016/j.cirp.2012.05.002

Gamage, J.R., DeSilva, A.K.M., 2016. Effect of Wire Breakage on the Process Energy Utilisation of EDM. Procedia CIRP, 18th CIRP Conference on Electro Physical and Chemical Machining (ISEM XVIII) 42, 586-590. doi:10.1016/j.procir.2016.02.264

Gamage, J.R., DeSilva, A.K.M., Harrison, C.S., Harrison, D.K., 2016. Process level environmental performance of electrodischarge machining of aluminium (3003) and steel (AISI P20). J. Clean. Prod. doi:10.1016/j.jclepro.2016.07.090

Garg, R.K., Aggarwal, V., Singh, S., 2014. Effect of Wire Materials on Cutting Performance of WEDM for Machining of Inconel Superalloy. Appl. Mech. Mater. 624, 124-128. doi:http://dx.doi.org.gcu.idm.oclc.org/10.4028/www.scientific.net/AMM.624.124

GHGPROTOCOL, 2017. Greenhouse Gas Protocol [WWW Document]. URL http://www.ghgprotocol.org/ (accessed 4.6.17).

Gutowski, T., Dahmus, J., Thiriez, A., 2006. Electrical energy requirements for manufacturing processes, in: 13th CIRP International Conference on Life Cycle Engineering, Leuven, Belgium. pp. 560564.

Ho, K.., Newman, S.., Rahimifard, S., Allen, R.., 2004. State of the art in wire electrical discharge machining (WEDM). Int. J. Mach. Tools Manuf. 44, 1247-1259. doi:10.1016/j.ijmachtools.2004.04.017 
Huang, J.T., Liao, Y.S., 2003. Optimization of machining parameters of Wire-EDM based on Grey relational and statistical analyses. Int. J. Prod. Res. 41, 1707-1720. doi:10.1080/1352816031000074973

IEA, 2016. Key World Energy Statistics 2016 [WWW Document]. URL https://www.iea.org/publications/freepublications/publication/KeyWorld2016.pdf (accessed 12.14.16).

Jones, E., 2017. How Many Working Days for Calculating Allowances? [WWW Document]. URL http://www.aboutemployeebenefits.co.uk/how-many-working-days-for-calculatingallowances.html (accessed 4.4.17).

Kellens, K., Renaldi, Dewulf, W., Duflou, J.R., 2011. Preliminary Environmental Assessment of Electrical Discharge Machining, in: Hesselbach, J., Herrmann, C. (Eds.), Glocalized Solutions for Sustainability in Manufacturing. Springer Berlin Heidelberg, pp. 377-382.

Li, W., Kara, S., 2015. Characterising Energy Efficiency of Electrical Discharge Machining (EDM) Processes. Procedia CIRP, The 22nd CIRP Conference on Life Cycle Engineering 29, 263-268. doi:10.1016/j.procir.2015.01.039

Manna, A., Bhattacharyya, B., 2006. Taguchi and Gauss elimination method: A dual response approach for parametric optimization of CNC wire cut EDM of PRAISiCMMC. Int. J. Adv. Manuf. Technol. 28, 67-75. doi:10.1007/s00170-004-2331-0

MET OFFICE, F.R., 2016. Regional values - October 2015 [WWW Document]. Met Off. URL http://www.metoffice.gov.uk/climate/uk/summaries/2015/october/regional-values (accessed 4.5.17).

Munoz, A.A., Sheng, P., 1995. An analytical approach for determining the environmental impact of machining processes. J. Mater. Process. Technol. 53, 736-758.

NeoNickel, 2016. Ti-6Al-4V [WWW Document]. URL http://www.neonickel.com/alloys/titaniumalloys/ti-6al-4v/ (accessed 12.7.16).

Pusavec, F., Krajnik, P., Kopac, J., 2010. Transitioning to sustainable production - Part I: application on machining technologies. J. Clean. Prod. 18, 174-184. doi:10.1016/j.jclepro.2009.08.010

Special Metals Corporation, 2007. Inconel alloy 718 [WWW Document]. URL http://www.specialmetals.com/assets/documents/alloys/inconel/inconel-alloy-718.pdf (accessed 6.12.16).

Sutherland, J.W., Gunter, K.L., 2001. Environmental Attributes of Manufacturing Processes, in: Madu, C.N. (Ed.), Handbook of Environmentally Conscious Manufacturing. Springer US, pp. 293-316.

Tarng, Y.S., Ma, S.C., Chung, L.K., 1995. Determination of optimal cutting parameters in wire electrical discharge machining. Int. J. Mach. Tools Manuf. 35, 1693-1701. doi:10.1016/08906955(95)00019-T

USEIA, 2016. Energy Use in Industry [WWW Document]. URL http://www.eia.gov/energyexplained/index.cfm/data/index.cfm?page=us_energy_industry (accessed 12.14.16).

WRI, 2011. WRI/WBCSD Greenhouse Gas Protocol (GHGP) | World Resources Institute [WWW Document]. URL http://www.wri.org/resources/videos/wriwbcsd-greenhouse-gas-protocolghgp (accessed 4.6.17). 